\title{
Infusing Self-Care and Wellness into CACREP Curricula: Pedagogical Recommendations for Counselor Educators and Counselors during COVID-19
}

\author{
John J. S. Harrichand ${ }^{1}$ (D) Stacey Diane Arañez Litam² $^{2} \cdot$ Clark D. Ausloos $^{3}$ (D)
}

Accepted: 26 January 2021 / Published online: 15 February 2021

(c) The Author(s), under exclusive licence to Springer Science+Business Media, LLC part of Springer Nature 2021

\begin{abstract}
Although self-care and wellness practices are important in counselor education, they have yet to be mapped and incorporated into the CACREP curriculum. Counselor educators are called to teach and model these practices for counselors in training (CIT) in a post-pandemic reality. The authors provide specific recommendations for integrating self-care and wellness practices across the CACREP curriculum in counselor education training programs, as well as pragmatic approaches for professional counselors, to address the paucity of literature.
\end{abstract}

Keywords COVID-19 · Self-care · Wellness · CACREP standards · Professional counselors

\section{Introduction}

The coronavirus disease (COVID-19) is the largest pandemic event of the twentyfirst century (Schild et al. 2020). As of February 5, 2021, approximately 104.5 million cases of COVID-19 and more than 2,271,000 deaths have occurred globally (World Health Organization 2021). In the United States, over 26 million cases have been confirmed resulting in over 443,200 deaths. The harmful effects of pandemic-related stress include changes in quality and patterns of sleep, difficulty concentrating, increased use and abuse of substances, mental health disorders, and suicide (Centers for Disease Control and Prevention [CDC] 2020; Thakur and Jain

John J. S. Harrichand

jharrichand@brockport.edu

1 Department of Counselor Education, State University of New York At Brockport, 350 New Campus Drive, Brockport, NY 14420, USA

2 Counseling, Administration, Supervision, and Adult Learning Department, Cleveland State University, Cleveland, OH, USA

3 Department of Counseling, Palo Alto University, Palo Alto, CA, USA 
2020). The deleterious effects of social isolation, pandemic related anxiety, lifestyle changes, economic problems, fear of poverty and homelessness, and instances of COVID-19 related racial discrimination may also compound in ways that increase rates of mental health distress (Litam 2020; Litam and Oh 2020; Litam and HipolitoDelgado 2021; Fiorillo and Gorwood 2020).

Professional counselors are called to consider how providing services amid a pandemic may create barriers for self-care and wellness and actively employ strategies to cultivate resilience (Litam et al. 2021). Similarly, counselor educators must prepare counselors-in-training (CITs) to engage in self-care practices and increase competency in using alternative forms of service delivery, such as telehealth services. Counselor educators are additionally called to prepare CITs to establish routine mental health and wellness practices to manage personal stress (American Counseling Association [ACA] 2014; Council for Accreditation of Counseling and Related Educational Programs [CACREP] 2015) stemming from COVID-19 (Gleeson 2020). According to the 2016 CACREP standards, counselor educators are tasked with preparing CITs and supervisees to incorporate self-care strategies that are applicable to their role as counselors (Section 2.1, CACREP 2015). Counselor educators who intentionally work to instill healthy wellness practices in CITs increase the resilience of future professional counselors who consequently are better positioned to be models of wellness for their clients (Hollingsworth 2015).

Challenges exist related to the underlying assumption that counselor educators are themselves models of self-care and wellness for their CITs (Moate et al. 2016). Counselor educators navigating experiences of COVID-19 related stress may struggle to balance their roles as educators, professional counselors, and supervisors in ways that result in the neglect of their own self-care practices. When counselor educators and supervisors neglect their own self-care and wellness, their abilities to model ethical practices and work effectively as counselor educators are compromised (Yager and Tovar-Blank 2007). In response to the unique challenges that affect counselors, counselor educators, and CITs during the COVID-19 pandemic, this article aims to do the following: 1. Outline the importance of self-care and wellness strategies for counselors and CITs during the COVID-19 pandemic, 2. Map self-care and wellness strategies onto the CACREP curricula, and 3. Describe specific strategies for professional counselors and CITs to cultivate self-care, promote resilience, and mitigate the effects of stress while providing services during the COVID-19 pandemic.

\section{Wellness and COVID-19}

Burnout refers to a state of physical, emotional, and mental exhaustion that occurs through emotionally demanding decisions (Pines and Aronson 1988), and impacts an individual's capacity to care (Rossi et al. 2012). In counseling, wellness is viewed holistically, and refers to the optimal functioning of the body, mind, and spirit (Myers et al. 2001). On the other hand, self-care refers to healthy activity or activities an individual engages in to refill and refuel oneself (Gentry 2002). Research conducted by Wester et al. (2009) concluded that although counselor educators 
appear to have high levels of wellness, their wellness and self-care practices may not be effectively transmitted to the counselors they train. For instance, in 2014 a joint report by the Continental National American (CAN) and Healthcare Providers Service Organization (HPSO) spanning a 10-year period, indicated that a little over $17 \%$ of all closed claims totaling almost $\$ 2,900,000$ concerned allegations related to Section C: Professional Responsibility of the ACA Code of Ethics, which stipulates that counselors must engage in self-care practices to maintain the overall well-being needed to meet their professional obligations. Counselors may experience high levels of burnout and impairment because they are less likely to implement self-care and wellness practices in their personal lives, yet they encourage their clients to do so (Meyers 2015). The unique challenges associated with providing services amid the COVID-19 pandemic may also create additional burdens for professional counselors that increase their risk for post-traumatic stress and decrease professional quality of life (Litam et al. 2021).

Extant research examining burnout in mental health services (Morse et al. 2012) documented that as many as $66 \%$ of mental health professionals may be facing high levels of burnout. The importance of cultivating self-care and resilience among professional counselors who provide services during natural disasters has been clearly established (Lambert and Lawson 2013). A recent study reported a strong negative association between post-traumatic stress and perceived stress on the overall quality of life among professional counselors $(N=161)$ providing services during the COVID-19 pandemic (Litam et al. 2021). Higher levels of counselor resilience were also strongly associated with compassion satisfaction and were negatively linked to burnout (Litam et al. 2021). Burnout experiences extend beyond counselors and may also impact CITs. Harrichand and colleagues (Harrichand et al. 2017) explained that examples of CITs burnout included hesitance to see clients, difficulty building rapport, avoidance of emotionally charged issues, and demonstrating an unwillingness to experience affect in relation to the clients' therapeutic process. Empirical studies have yet to determine how many counseling programs are integrating self-care and wellness practices into their core courses, stressing the importance for counselor educators to emphasize the value of maintaining wellness (Dye et al. 2020), especially following the COVID-19 pandemic.

Taken together, the previous literature illuminates the importance for counselor educators to instill self-care and wellness practices in CITs while emphasizing ongoing reflection for professional counselors. The importance of reflecting on ones' needs and cultivating resilience becomes especially critical when professional counselors provide services during the COVID-19 pandemic (Litam et al. 2021). Although the long-term impacts of shelter-in-place, lockdown, isolation, and social distancing orders on counselors, counselor educators, and CITs remain forthcoming, the mental health profession has needed to adjust and adapt in considerable ways that may interfere with regular wellness practices. For example, counselor educators and CITs were forced to quickly adapt to unplanned extended breaks, navigate disruptions in their learning environments, and quickly learn new technologies to continue the educational and learning process (Bray 2020). Similarly, counselors were forced to adapt to telehealth services, navigate new ethical concerns related to virtual counseling and HIPAA compliant platforms, and negotiate challenges 
of working from home without a dedicated home office (Litam et al. 2021). The compounding effects of COVID-19 related stressors may interfere with counselors', counselor educators', and CITs' abilities to engage in regular self-care and wellness practices as more existential concerns, such as fear of illness, death and dying, separation from family members and friends, and financial distress loom overhead.

\section{ACA Code of Ethics}

The ACA Code of Ethics (2014) enables the ACA to carry out its mission of "enhancing the quality of life in society by promoting the development of professional counselors, advancing the counseling profession, and using the profession of counseling to promote respect for human dignity and diversity" (p. 2). As professional counselors, a fundamental aspect of our professional development encompasses areas of self-care and wellness. Section $C$ states, "counselors engage in selfcare activities to maintain and promote their own emotional, physical, mental, and spiritual well-being to best meet their professional responsibilities" (ACA 2014, p. 8 ). The code further addresses counselor educators, who are charged as mentors and role models for CITs in Section F: Standard 7. Therefore, professional counselors are required to engage in self-care and wellness practices and counselor educators are called to model appropriate self-care and wellness practices while ensuring CITs are intentionally engaging in their own practices and are competent in promoting the wellbeing of their clients (Coaston and Cook 2018).

\section{ACES Competencies for Supervision}

Counselor educators and supervisors foster self-awareness, personal growth, and wellness into their CITs through the supervisory relationship (Witmer and Young 1996; Yager and Tovar-Blank 2007) and are guided by Best Practices in Clinical Supervision (Association for Counselor Education and Supervision [ACES] 2011). This document contains 12 sections that outline the phases and processes of clinical supervision, training, characteristics, and behaviors of competent supervisors and complement the ACA Code of Ethics. Under the Supervision Best Practice Guidelines, Section 7. Ethical Considerations b.vi, "the supervisor appropriately engages in and models self-care" (ACES 2011, p. 10), which is reemphasized in Section 11-The Supervisor d.xiii. Self-care is of central importance for counselor educators and supervisors due to the responsibility they carry as leaders and models for CITs and supervisees. If counselor educators and supervisors become impaired from COVID-19 related stress, they are not only engaging in unethical practice by failing to uphold the values of the counseling profession, but they may also be modeling poor practice. Ultimately, counselor educators and supervisors must prepare students to meet the mental health needs of their clients (Harrichand et al. 2021; Hill 2004). The presence of unresolved stress in counseling supervisors can negatively impact the gatekeeping and remediation practices of counseling programs and the clients served by CITs (Homrich 2018). Given that the counseling profession was founded on wellness (Myers and Sweeney 2005), it remains of critical importance 
for counselor educators, professional counselors, and CITs to incorporate self-care and wellness practices into their CES curriculum and daily lives, especially following the emergence of the COVID-19 pandemic.

\section{Mapping Self-Care and Wellness into CES Curriculum}

Counselor educators are expected to have the baseline knowledge required to navigate leadership positions and demonstrate evidence-based protocols and strategies for responding to crisis and trauma while maintaining their own self-care and wellness (ACES 2011; CACREP 2015). It is therefore implied that counselor educators holding faculty positions in CACREP-accredited programs demonstrate competence in teaching counseling graduate students to work effectively with clients during a crisis (Levers 2020), while promoting and reinforcing self-care and wellness practices through the supervisory relationship (Hyatt-Burkhart 2019). The demanding nature of counseling in a post-pandemic era necessitates special consideration for counselor educators and supervisors to highlight the value of self-care in counselors and CITs.

\section{Deficits of Self-Care and Wellness Language}

Before mapping self-care and wellness onto CES curricula, the authors examined extant literature and found only a single mention of self-care in the 2016 CACREP Standards (CACREP 2015) directed towards professional counselors. Similarly, selfcare for counselors is only mentioned once in the ACA Code of Ethics (2014), and it is identified as an encouraged practice rather than as a mandate. The term wellness was identified three times across the CACREP standards; first, under Section 2: Professional Counseling Identity, Counseling Curriculum, 3.Human Growth and Development, counseling programs are tasked with ensuring "i. ethical and culturally relevant strategies for promoting resilience and optimum development and wellness across the lifespan" (p. 11). Second, under Section 5: Entry-Level Specialty Areas, A. Addiction Counseling, 2. Contextual Dimensions, counseling programs should educate CITs on the "f. role of wellness and spirituality in the addiction recovery process" (p. 19). Finally, under Section 5, F. Marriage, Couple, and Family Counseling, 3. Practice, counseling programs are charged with educating CITs in "fostering family wellness" (p. 31).

Although CACREP does not create explicit guidelines for programs to integrate its standards, the paucity of language regarding counselor self-care in the ACA Code of Ethics (2014) and CACREP (2015) standards, may illuminate a possible gap between the expectations and actual practice of self-care and wellness. It is notable that a profession grounded in wellness places little emphasis on counselors, counselor educators, and CITs, to incorporate self-care and wellness practices into their personal lives (Coaston and Cook 2018), which may lead to burnout (Coaston 2017). Establishing self-care and wellness strategies is therefore of paramount importance and must be infused across the CACREP curriculum to mitigate 
the deleterious effects of stress and decrease counselor burnout, especially following the emergence of COVID-19. Although there has been a push for counselors to focus on the positive effects of their work as helpers (Hyatt-Burkhart 2019), the CACREP curriculum lacks guidance for counseling programs to integrate self-care and wellness practices across the curriculum. The importance of instilling self-care and wellness practices in CITs early in their professional development is of utmost importance given the challenges, burdens, and mental health implications following COVID-19 (Litam 2020; Litam and Hipolito-Delgado 2021; Fiorillo and Gorwood 2020; Thakur and Jain 2020). The following sections provide recommendations that may be used to meet a specific CACREP standard, whereas others can be used to meet multiple standards. With this caveat in mind, practical strategies for counselor educators to incorporate self-care and wellness topics following COVID19 across the CACREP curriculum are provided. It is important to note that the selfcare and wellness recommendations provided can also be implemented by practicing counselors.

\section{Recommendations for Infusing Self-Care and Wellness Across CACREP Core Standards}

\section{Section 2.F.1 Professional Counseling Orientation and Ethical Practice}

According to Section 2.F.1., counselor educators are explicitly tasked with ensuring CITs are knowledgeable of "self-care strategies appropriate to the role of the counselor" (CACREP 2015, p. 10). This section of the CACREP Standards also references the ACA Code of Ethics (2014) and the importance of ethical practice. One way faculty can integrate self-care and wellness to meet criteria (Section 2.F.1.l and $m$ ) following COVID-19 is to invite students to engage in written self-reflection on their current self-care and wellness strategies and describe how they are linked to evidence-based wellness models (e.g., Sweeney and Myers 2003). CITs can additionally consider how social distancing requirements related to the pandemic may hinder previously established wellness strategies and identify creative ways to adapt their self-care practices. This assignment can also encourage students to begin developing reflective thinking skills (Griffith and Frieden 2000) by exploring how adapted self-care and wellness practices following the pandemic may be incorporated and modified into their future roles as professional counselors. As counseling programs train CITs in light of the COVID-19 pandemic, this assignment may additionally require CITs to reflect on the role self-care and wellness practices serve in navigating pandemic-related anxiety (Fiorillo and Gorwood 2020; Gleeson 2020).

Counselor educators may additionally combine self-care and wellness curricula with ethical considerations (Section 2.F.1.i) by helping students identify self-care strategies that may mitigate the likelihood of counseling impairment during COVID19 across each of the ACA Code of Ethics (2014) areas. The assignment can culminate in CITs creating a wellness-plan that they can revise as they progress through the program, ultimately illuminating the importance of developmental wellness within the counseling profession (Witmer and Young 1996). With this assignment, 
CITs may be encouraged to review relevant research and report how professional counseling associations and credentialing and licensure boards (Section 2.F.1.f and $g$ ) are supporting counseling students, counselors, counselor educators, and counseling supervisors by promoting self-care and wellness practices following the COVID-19 pandemic. This assignment can be tailored to promote self-care in a post-pandemic reality by asking CITs to assess the ways in which their ethical roles as professional counselors may be impacted as a result of COVID-19. They can then build their wellness-plans to include self-care and wellness practices that cater to the unique identified barriers arising from the pandemic. Finally, CITs can gather pandemic-related self-care and wellness resources by researching counseling organizations, ACA divisions, the National Board for Certified Counselors, state licensure boards, the American School Counselor Association [ASCA], and the National Institute of Mental Health [NIMH]). Due to the scope of this assignment, faculty are encouraged to disseminate the assignment across a semester or throughout an internship course. Counselor educators may award credit as tasks are completed to ensure CITs have the time and energy necessary to intentionally invest in each task.

\section{Section 2.F.2 Social and Cultural Diversity}

The power of globalization and growing access to information provides people with increasing opportunities to learn about new groups, cultures, and practices. Counselor educators who teach multicultural courses are tasked with educating CITs about the value of diversity and the importance of theories and models related to multicultural counseling (Section 2.F.2.a, b, and c). One assignment for CITs is to read and discuss the Multicultural and Social Justice Counseling Competencies (MSJCC; Ratts et al. 2015) as a class. CITs may be asked to build upon their personalized wellness plan from Section 2.F.1 by documenting how Ratts and colleagues' (Ratts et al. 2015) four domains (counselor self-awareness, client worldview, counseling relationship, and counseling and advocacy interventions) can all be enhanced by incorporating active self-care practices following the pandemic. Additionally, CITs can examine how their wellness plan is impacted by COVID-19 across each of the four domains and identify creative strategies to adapt their plan.

The COVID-19 pandemic disproportionately affects Black, Indigenous, and People of Color (BIPOC) communities (Litam and Hipolito-Delgado 2021) and has contributed to higher rates of COVID-19 related racial discrimination among Asians, Asian American, and Pacific Islander communities (Litam 2020; Litam and Oh 2020). Counselor educators must consider how experiences of ongoing racial discrimination and systemic racism may negatively impact self-care and wellness practices among BIPOC students and CITs. Counselor educators can incorporate selfcare and wellness content into the curricula by helping students and CITs explore the protective effects of culturally congruent coping strategies, identify supportive racial and ethnic communities, and outline strategies to cultivate strong racial and ethnic identities. Counselor educators are additionally encouraged to prepare CITs to work effectively with BIPOC, Asian, Asian American, and Pacific Islander clients who face specific race-related challenges and higher rates of race-based trauma 
following the pandemic (Anandavalli et al. 2020; Litam 2020; Litam and HipolitoDelgado 2021). To facilitate this process, CIT's can be assigned to groups and brainstorm how racial, ethnic, social, cultural, spiritual, and other salient and non-salient identities combine in ways that influence power, privilege, and oppression, and impact self-care and wellness - individually and collectively during the COVID-19 pandemic.

Counselor educators can extend these assignments by having CITs examine the ways in which their own gender identities and/or spiritual and religious identities are further impacted by COVID-19 and pandemic-related stress. For example, transgender folx who face housing concerns and barriers to care may also be disproportionately affected by the COVID-19 pandemic (Litam and Hipolito-Delgado 2021) and religious individuals who are unable to physically congregate and engage in spiritual, religious, and cultural practices may be less inclined to engage in self-care and wellness practices (Gjelten 2020). Counselor educators may therefore encourage CITs to identify pandemic-related resources for transgender and religious folx who may be in need of support and lack accessibility to treatment and housing services.

\section{Section 2.F.3 Human Growth and Development}

Counselor education faculty teaching human development courses are tasked with ensuring CITs have an understanding of human development across the lifespan, which encompasses developmental challenges including addictions, crisis and trauma and the promotion of optimal growth (CACREP 2015, Section 2.F.3). One common assignment in this course is to conduct a developmental interview (Capuzzi and Stauffer 2016) on a specific age group and complete a written assignment that addresses the developmental history, ability status, and culture, among other characteristics. Counselor educators can infuse self-care and wellness paradigms following the COVID-19 pandemic by explicitly asking CITs to explore how the interviewee effectively copes and develops resilience in relation to crisis and trauma (Section 2.F.3 $g$ and i), including during COVID-19. The assignment may include a section where CIT's reflect on how they might incorporate self-care and wellness strategies following COVID-19 and identify the expected benefits of these strategies across the lifespan. Faculty should ensure that the group(s) chosen by CITs are treated with dignity and respect, and provide their consent (where applicable). Special consideration is additionally needed to ensure proper social distancing recommendations are met during interviews to minimize the risk of infection.

Encouraging CITs to engage in their own personal counseling reflects another strategy that can be used to meet Section 2.F.3. Counselor educators may ask CITs to reflect on the value of personal counseling in light of the global impact of COVID-19 (Thakur and Jain 2020). CITs can reflect on how they might continue to benefit from self-care practices as a professional counselor in ways that develop resilience and wellness (Gleeson 2020; Yager and Tovar-Blank 2007). Likewise, counselor educators should intentionally and regularly facilitate classroom discussions on the importance of self-care and wellness in relation to human and counselor development (Corey et al. 2017), and examine how these practices may be adapted 
in COVID-19. CITs can be tasked with creating collages that capture their biological development (i.e., birth to present) coupled with activities/events that demonstrated self-care and wellness. They can include a brief reflection documenting how self-care and wellness impacted each specific stage of development (Section 2.F.3 $g$ and $i$ ). The final reflection within the collage can address how the CIT plans to draw on past self-care and wellness practices when faced with challenges, including prolonged crises like COVID-19, as a professional counselor. Care should be taken to minimize CITs from experiencing/re-experiencing past triggering events as they reflect on their biological development, and/or safeguards (e.g., referrals to personal counseling) provided prior to working with clients (Yager and Tovar-Blank 2007).

\section{Section 2.F.4 Career Development}

Counselor educators can use career well-being prompts to help CITs reflect on their work environment and life experiences following COVID-19. Examples of prompts include, "Do you like what you do each day as a CIT/future professional counselor providing services in COVID-19?", "How might counseling during a pandemic impact your mental health and well-being?", "How might you minimize barriers to employment opportunities during the pandemic?", "How might you apply these insights to current and future clients?" (adapted from Jones and Jones 2016). Counselor educators may additionally encourage CITs to use information obtained from Section 2.F.4 $b$ "approaches for conceptualizing the interrelationships among and between work, mental well-being, relationships, and other life roles and factors" (CACREP 2015) to inform their personal self-care and wellness plan addressed in Section 2.F.1 above.

\section{Section 2.F.5 Counseling and Helping Relationships}

According to Section 2.F.5, counselor educators must ensure CITs gain the knowledge and skills of counseling theories and demonstrate ethical and cultural competence in establishing and maintaining the therapeutic relationship (CACREP 2015). CITs are also required to have knowledge and skill in client conceptualization and development of collaborative treatment plans (CACREP 2015). Counselor educators who instruct theories courses can incorporate self-care and wellness into their assignments by asking CITs to describe their personal theoretical orientation and outline how promoting of self-care and wellness practices is consistent with their guiding theory and affects their work with clients (Section 2.F.5 h and j). As explained by Yager and Tovar-Blank (2007), wellness needs to be modeled and presented as a lifestyle choice. Therefore, the assignment guidelines might include a prompt asking the CIT to comment on how they plan on modeling self-care and wellness as a professional counselor (Section 2.F.5 f), especially during COVID-19.

In a diagnosis and treatment planning course, counselor educators can also help CITs apply the value of personal self-care and wellness when supporting clients with severe mental health concerns or high-risk clients (Section 2.F.5 j) impacted by COVID-19. Counselor educators can have CITs identify client strengths and 
resilience (Witmer and Young 1996; Yager and Tovar-Blank 2007) when completing a biopsychosocial report. CITs may also be tasked with finding creative ways of intentionally incorporating self-care and wellness in treatment plans in keeping with "positive humanistic views of human nature" (Yager and Tovar-Blank 2007, p. 152) (Section 2.F.5 b) and client empowerment. Finally, CITs may be asked to conceptualize how pandemic related experiences may contribute to diagnoses.

Within clinical experience courses such as practicum and internship, counselor educators can further incorporate self-care and wellness into assignments. For example, assignments may include pre- and post- plans, wherein CITs create selfcare and wellness plans for themselves at the beginning of the clinical experience and modify their existing plan to account for COVID-19 related challenges at a later date. Towards the end of their clinical experiences, CITs may be asked to incorporate their insights and revise their self-care and wellness plan, through self-evaluation, to strengthen areas of weakness and identify areas of strength (Witmer and Young 1996) (Section 2.F.5 f).

\section{Section 2.F.6 Group Counseling and Group Work}

Examining Section 2.F.6, counselor education faculty teaching a group counseling course are tasked with ensuring CITs have the knowledge and skills needed to facilitate effective groups (CACREP 2015). Group counseling courses usually include experiential activities where students learn group dynamics through active participation and/or observation (Corey 2020). For example, faculty can incorporate selfcare and wellness practices by having CITs form groups and demonstrate socially distant self-care or wellness techniques that can be safely implemented in real-world settings.

\section{Section 2.F.7 Assessment and Testing}

Counselor educators teaching an assessment and testing course are charged with educating CITs on the meaning, preparation, use, and application of tests and assessments (Section 2.F.7). They are also tasked with ensuring CITs develop the knowledge and skills to utilize and interpret statistical concepts (CACREP 2015). The COVID-19 pandemic has expanded the use of telehealth and distance-counseling services, and counselor educators should address the use of assessments and screening tools (specifically related to trauma) delivered in these modalities (Briere et al. 2020). Additionally, counselor educators should introduce CITs to extant self-care and wellness assessments and screening tools for themselves, as well as for future clients (i.e., Wellness Inventory [WI], Life Coping Inventory [LCI], Five-factor WEL [5F-Wel]; Bart et al. 2018). 


\section{Incorporating Wellness Among Professional Counselors}

While this article emphasizes attention to counselor educators and CITs in training programs, professional counselors can also benefit from increased self-care and wellness practices. Several of the interventions recommended by the authors can be modified to suit the needs of professional counselors. For example, professional counselors can engage in intentional written self-reflections that outline their own self-care and wellness strategies, review the ACA Code of Ethics (2014) to recall the importance of self-care, and create a professional wellness plan. When providing counseling services during the COVID-19 pandemic, professional counselors must extend the same compassion to themselves that they afford to their clients. Just as professional counselors encourage their clients to engage in self-care practices, counselors can additionally commit to wellness by limiting their exposure to social media and news outlets, cultivating resilience, setting boundaries, engaging in physical activities, eating balanced and nutritious meals, practicing good sleep hygiene, and leveraging emotional and supportive resources (Litam et al. 2021).

Professional counselors who provide counseling services during the pandemic may be at higher risks for post-traumatic stress and burnout (Litam et al. 2021). Thus, professional counselors are encouraged to pursue their own individual counseling services, when necessary, and seek supervision and/or peer supervision to unpack complex and unprecedented client cases. BIPOC counselors who may be disproportionately affected by the COVID-19 pandemic may benefit from leveraging support from racial, ethnic, and/or religious communities that bolster group identities, validate shared experiences of oppression, and encourage the use of culturally congruent self-care strategies and coping responses (see Litam 2020; Litam and Hipolito-Delgado 2021).

\section{Future Directions}

The current manuscript outlines specific examples of self-care and wellness practices that counselor educators can incorporate into CACREP (2015) standards and illuminates the importance of integrating self-care to mitigate burnout among professional counselors during COVID-19. Further evaluation is needed to discern strategies that cultivate self-care and wellness practices at the doctoral level. Areas of additional study may examine the specific areas of resilience that BIPOC counselors and counselor educators have developed while providing services during COVID-19 that decrease stress and buffer empathic occupational hazards. Finally, future areas of study may examine whether the identified self-care strategies are effective in mitigating the effects of burnout among counselors practicing during COVID-19 in a longitudinal study. 


\section{Conclusion}

The following article outlined the importance of incorporating wellness and selfcare practices into the CACREP (2015) curriculum and emphasized the necessity for counselor educators and supervisors to prepare CIT's who will provide services during the COVID-19 pandemic. Counselor educators, supervisors, and counselors are additionally encouraged to engage in wellness and self-care strategies to maintain professional and ethical practice and model the importance of self-care, especially in times of crisis, i.e., navigating live during COVID-19. Just as professional counselors encourage self-compassion and illuminate the deservingness of self-care to our clients, professional counselors and counselor educators must also demonstrate these skills in their own lives while embedding them into CACREP-accredited counselor education programs.

\section{Declarations}

Conflict of Interest We have no known conflicts of interest to disclose.

\section{References}

American Counseling Association. (2014). ACA code of ethics. Author.

Association for Counselor Education and Supervision. (2011). Best practices in clinical supervision. https://acesonline.net/wp-content/uploads/2018/11/ACES-Best-Practices-in-Clinical-Supervisio n-2011.pdf.

Anandavalli, S., Harrichand, J. J. S., \& Litam, S. D. A. (2020). Counseling international students in times of uncertainty: A critical feminist and bioecological approach. The Professional Counselor: Research and Practice, 10(3), 365-375. https://doi.org/10.15241/sa.10.3.365.

Bart, R., Ishak, W. W., Ganjian, S., Jaffer, K. Y., Abdelmesseh, M., Hanna, S., Gohar, Y., Azar, G., Vanle, B., Dang, J., \& Danovitch, I. (2018). The assessment and measurement of wellness in the clinical medical setting: A systematic review. Innovations in Clinical Neuroscience, 15(9-10), 14-23. https ://www.ncbi.nlm.nih.gov/pmc/articles/PMC6292717/pdf/icns_15_9-10_14.pdf.

Bray, B. (2020). Counseling's evolution under COVID-19. Counseling Today, 62(12), 18-25. https:// ct.counseling.org/2020/05/counselings-evolution-under-covid-19/.

Briere, J., Lanktree, C., \& Escott, A. (2020). Trauma teletherapy for youth in the era of the COVID-19 pandemic: Adapting evidence-based treatment approaches. University of Southern California. https ://keck.usc.edu/adolescent-trauma-training-center/wp-content/uploads/sites/169/2020/07/Traum a_Teletherapy_Final_2020702.pdf.

Capuzzi, D., \& Stauffer, D. M. (2016). Human growth and development across the lifespan: Applications for counselors. Hoboken: Wiley.

Centers for Disease Control and Prevention. (2020). Stress and coping. https://www.cdc.gov/coronaviru s/2019-ncov/daily-life-coping/managing-stress-anxiety.html.

Coaston, S. C. (2017). Self-care through self-compassion: A balm for burnout. The Professional Counselor, 7(2), 285-297. https://doi.org/10.15241/scc.7.3.285.

Coaston, S. C., \& Cook, E. P. (2018). Burnout in counselor education: The role of cynicism and fit in predicting turnover intention. The Journal of Counselor Preparation and Supervision, 10(1), 1-27. https://repository.wcsu.edu/jcps/vol10/iss1/8.

Continental National American, \& Healthcare Providers Service Organization. (2014). Understanding counselor liability risk. http://www.hpso.com/Documents/pdfs/CNA_CLS_COUNS_022814p_CF_ PROD_ASIZE_online_SEC.pdf.

Corey, G. (2020). Theory and practice of group counseling (9th ed.). Boston: Cengage. 
Corey, G., Muratori, M., Austin, J. T., \& Austin, J. A. (2017). Counselor self-care. New York: Wiley.

Council for Accreditation of Counseling and Related Educational Programs. (2015). 2016 CACREP standards. Author.

Dye, L., Burke, M. G., \& Wolf, C. (2020). Teaching mindfulness for the self-care and well-being of counselors-in-training. Journal of Creativity in Mental Health, 15(2), 140-153. https://doi. org/10.1080/15401383.2019.1642171.

Fiorillo, A., \& Gorwood, P. (2020). The consequences of the COVID-19 pandemic on mental health and implications for clinical practice. European Psychiatry, 63(1), e32, 1-2. https://doi.org/10.1192/j. eurpsy.2020.35

Gentry, J. E. (2002). Compassion fatigue: A crucible of transformation. Journal of Trauma Practice, 1(34), 37-61. https://doi.org/10.1300/J189v01n03_03.

Gjelten, T. (2020). Things will never be the same. How the pandemic has changed worship. National Public Radio: WNYC. Special Series: The Coronavirus Crisis. https://www.npr.org/2020/05/20/85891 8339/things-will-never-be-the-same-how-the-pandemic-has-changed-worship.

Gleeson, S. (2020). The revised meaning of self-care in the wake of COVID-19. Counseling Today Online. https://ct.counseling.org/2020/08/the-revised-meaning-of-self-care-in-the-wake-of-covid $-19 /$.

Griffith, B., \& Frieden, G. (2000). Facilitating reflective thinking in counselor education. Counselor Education and Supervision., 40(2), 82-93. https://doi.org/10.1002/j.1556-6978.2000.tb01240.x.

Harrichand, J. J. S., Knight, A. M., \& Captari, D. (2017). The impact of emotional intelligence on counselor burnout. Virginia Counselors Journal, 35, 40-47.

Harrichand, J. J. S., Thomas, J. C., Mwendwa, J. M., \& DiLella, N. M. (2021). Leadership and burnout: An analysis of counselor educators in CACREPaccredited programs in the United States. Journal of Counselor Leadership and Advocacy. https://doi.org/10.1080/2326716X.2021.18870 08. (in press).

Hill, N. R. (2004). The challenges experienced by pretenured faculty members in counselor education: A wellness perspective. Counselor Education and Supervision, 44(2), 135-146. https://doi. org/10.1002/j.1556-6978.2004.tb01866.x.

Hollingsworth, M. A. (2015). Wellness: Paradigm for training and practice. VISTAS Online, Article 39, 1-19. https://www.counseling.org/docs/default-source/vistas/article_39835c21f16116603abc acff0000bee5e7.pdf?sfvrsn=1d4a412c_8.

Homrich, A. M. (2018). Introduction to gatekeeping. In A. M. Homrich \& K. L. Henderson (Eds.), Gatekeeping in the mental health profession (pp. 1-24). Alexandria: American Counseling Association.

Hyatt-Burkhart, D. (2019). Counselor self-care and personal development. In L. L. Levels \& D. HyattBurkhart (Eds.), Clinical mental health counseling: Practicing in integrated systems of care (pp. 281-305). New York: Springer.

Jones, L. K., \& Jones, J. W. (2016). Career well-being: Defined and strengthened. Career Convergence Web Magazine. https://www.ncda.org/aws/NCDA/pt/sd/news_article/118635/_PARENT/ CC_layout_details/false.

Lambert, S., \& Lawson, G. (2013). Resilience of professional counselors following hurricanes Katrina and Rita. Journal of Counseling \& Development, 91(3), 261-268. https://doi.org/10.100 2/j.1556-6676.2013.00094.x.

Levers, L. L. (2020). Crisis, disaster, and trauma issues in clinical mental health counseling. In L. L. Levers \& D. Hyatt-Burkhart (Eds.), Clinical mental health counseling: Practicing in integrated systems of care (pp. 91-116). New York: Springer.

Litam, S. D. A. (2020). Take your kung-flu back to Wuhan: Counseling Asians, Asian Americans, and Pacific Islanders with race-based trauma related to COVID-19. The Professional Counselor, 10(2), 144-156. https://tpcjournal.nbcc.org/wp-content/uploads/2020/05/Pages-144-156-Litam -Take-Your-Kung-Flu-Back-to-Wuhan.pdf.

Litam, S. D. A., \& Oh, S. (2020). Effects of COVID-19 racial discrimination on Chinese Americans: Ethnic identity and coping strategy as moderators. Counseling Outcome Research and Evaluation. https://doi.org/10.1080/21501378.2020.1814138.

Litam, S. D. A., \& Hipolito-Delgado, C. P. (2021). When being "essential" illuminates disparities: Counseling clients affected by COVID-19. Journal of Counseling \& Development, 99(1), 3-10. https://doi.org/10.1002/jcad.12349. 
Litam, S. D. A., Ausloos, C. D., \& Harrichand, J. J. S. (2021). Stress and resilience among professional counselors during the COVID-19 pandemic. Journal of Counseling \& Development, 99(2). (in press).

Meyers, L. (2015). Stumbling blocks to counselor self-care. Counseling Today, 57(9), 30-37.

Moate, R. M., Gnilka, P. B., West, E. M., \& Bruns, K. L. (2016). Stress and burnout among counselor educators: Differences between adaptive perfectionists, maladaptive perfectionists, and nonperfectionists. Journal of Counseling \& Development, 94(2), 161-171. https://doi.org/10.1002/jcad.12073.

Morse, G., Salyers, M. P., Rollins, A. L., Monroe-DeVita, M., \& Pfahler, C. (2012). Burnout in mental health services: A review of the problem and its remediation. Administration and Policy in Mental Health and Mental Health Services Research, 39(5), 341-352. https://doi.org/10.1007/s1048 8-011-0352-1.

Myers, J. E., \& Sweeney, T. J. (Eds.). (2005). Counseling for wellness: Theory, research, and practice. American Counseling Association.

Myers, J. E., Sweeney, T. J., \& Witmer, J. M. (2001). Optimization of behavior: Promotion of wellness. In D. C. Locke, J. E. Myers, \& E. L. Herr (Eds.), The handbook of counseling (pp. 641-652). Sage.

Pines, A. M., \& Aronson, E. (1988). Career burnout. New York: Free Press.

Ratts, M. J., Sing, A. A., Nassar-McMillan, S., Butler, S. K., \& McCullough, J. R. (2015). Multicultural and social justice counseling competencies. http://www.counseling.org/knowledge-center/compe tencies.

Rossi, A., Cetrano, G., \& Pertile, R. (2012). Burnout, compassion fatigue, and compassion satisfaction among staff in community based mental health services. Psychiatry Residency, 2-3, 933-938.

Schild, L., Ling, C., Blackburn, J., Stringhini, G., Zhang, Y., \& Zannettou, S. (2020). "Go eat a bat, Chang!": An early look on the emergence of sinophobic behavior on web communities in the face of COVID-19. arXiv. https://arxiv.org/pdf/2004.04046.pdf.

Sweeney, T. J., \& Myers, J. E. (2003). The indivisible self: An evidence-based model of wellness. Authors.

Thakur, V., \& Jain, A. (2020). COVID-2019-suicides: A global psychological pandemic. Brain, Behavior, and Immunity. https://doi.org/10.1016/j.bbi.2020.04.062.

Wester, K. L., Trepal, H. C., \& Myers, J. E. (2009). Wellness of counselor educators: An initial look. The Journal of Humanistic Counseling, 48(1), 91-109. https://doi.org/10.1002/j.2161-1939.2009.tb000 70.x.

Witmer, J. M., \& Young, M. E. (1996). Preventing counselor impairment: A wellness approach. The Journal of Humanistic Counseling, 34(3), 141-155. https://doi.org/10.1002/j.2164-4683.1996.tb003 38.x.

World Health Organization. (2021, January 10). WHO coronavirus disease (COVID-19) dashboard. https ://covid19. who.int/?gclid=EAIaIQobChMIjdyKu9nP6QIVUNbACh3G0ggsEAAYASAAEgI6hP D_BwE.

Yager, G. G., \& Tovar-Blank, Z. G. (2007). Wellness and counselor education. Journal of Humanistic Counseling, Education and Development, 46(2), 142-153. https://doi. org/10.1002/j.2161-1939.2007.tb00032.x.

Publisher's note Springer Nature remains neutral with regard to jurisdictional claims in published maps and institutional affiliations. 